\title{
The dark side of E. coli
}

Last month, the president of fast-food chain Taco Bell appealed to his customers in fullpage ads in The New York Times and other US newspapers. "You can be confident our food is safe to eat," his letter declared.

The ads were the fallout from a food-poisoning outbreak traced to the chain's restaurants, which has affected at least 70 people across five states. The culprit was Escherichia coli O157:H7 - the same as in another outbreak this September and October linked to Californian spinach, which infected nearly 200 across the country and killed three.

The outbreaks have thrown the spotlight on a bacterium that is difficult to detect and virtually impossible to treat or eradicate. "We see it more and more and we don't really know what to do about it," says microbiologist John Fairbrother of the University of Montreal, Canada.

There are thousands of different strains of E. coli, most of which are harmless. But $\mathrm{O} 157$ can make a potent toxin and latch onto intestinal cells, giving it the ability to cause kidney failure and even death. The bugs live harmlessly in cows' large intestine and are thought to be ubiquitous in cattle lots. Bacteria shed in faeces contaminate meat in slaughterhouses or find their way onto vegetables grown near animals or irrigated with water contaminated with manure, as is thought to have happened with the tainted spinach. Lettuce is thought to have spread the Taco Bell outbreak.

There are now some promising research leads that might help prevent future outbreaks.
At a meeting earlier this year on pathogenic E. coli, veterinary researcher David Smith of the University of Nebraska, Lincoln, and his colleagues reported that a vaccine containing proteins from $\mathrm{O} 157$ cut the number of cows shedding bacteria by $60-70 \%$. Canadian company Bioniche Life Sciences, based in Belleville, Ontario, has submitted the vaccine for regulatory approval in Canada, and plans to do so in the United States.

Other groups are turning to viruses, called bacteriophages, that attack the $\mathrm{O} 157$ strain. A group led by microbiologist Todd Callaway of the US Department of Agriculture's Food and Feed Safety Research Unit in College Station, Texas, has found that feeding sheep a mixture of bacteriophages cuts the number of pathogenic bacteria in their guts by over 1,000 times.

Cattle farmers may be forced to adopt vaccines or therapies because of pressure from food processors and the threat of lawsuits. But some microbiologists question whether these

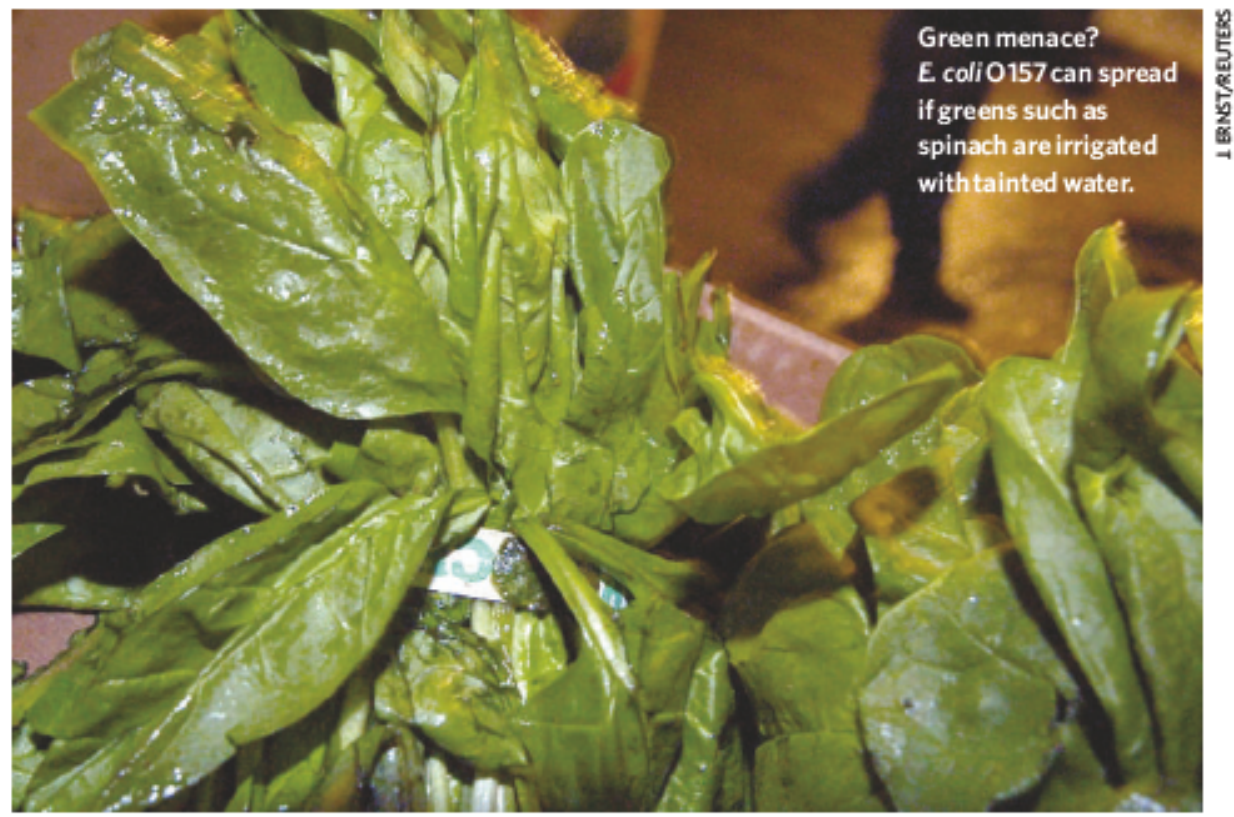

\section{European funding targets big biology}

Metagenomicsand the hum an variome project canexpect substantial boosts in the European Union's next round of science funding, starting this month.

Unlike its predecessors, which covered five-year periods, Framework Programme 7 (FP7) runs for seven years, until 2013. It has a budget of more than $\epsilon 50$ billion (US\$66 billion), of which two-thirds is earmarked for large public-private collaborations in ten areas, including health, transport and nanoscience.
The first calls for proposals went out on 22 December. For the health theme, the focus is on big biology. A planned metagenomics project, one large topic for the fir stcall, aims to study the vastcommunity of microbes living in the human body, which are thought to influence physiology, nutrition and immunity.

"There are some two kilograms of microorganisms living in the human body," says Dusko Ehrlich, a microbial geneticist at the French agricultural research agency INRA in Jouy-en-Josas. Most of them can't be grown in the lab: "We justdon't know what's in there." Proposals are requested for projects tosequence the microbial genes present in the body, which are thought to outnumber our own genes by a factor of 100 .

Another project ear marked for funding will support the global humanvariome project, which was launched in Melbourne, Australia, last June. The variome is the set of variations between different people's genomes, which influence the development of disease and drug side-effects. As yet there is no global system for collecting and sharing inform ation on the human variome; FP7 promises to supportone.

FP7 also provides $€ 7.5$ billion for a new Europe-wide funding agency called the European Research Council (ERC), which launches this month. The council will fund smaller projects that do not meet the industrial or societal goals required by the rest of the framework programme.

Nora Eichinger 
